\title{
Uncertainty Assessment for Management of Soil Contaminants with Sparse Data
}

\section{UTE SCHNABEL* \\ OLAF TIETJE \\ ROLAND W. SCHOLZ}

Chair of Environmental Science - Natural and Social Science Interface

Swiss Federal Institute of Technology

Haldenbachstr. 44

8092 Zurich, Switzerland

ABSTRACT / In order for soil resources to be sustainably managed, it is necessary to have reliable, valid data on the spatial distribution of their environmental impact. However, in practice, one often has to cope with spatial interpolation achieved from few data that show a skewed distribution and uncertain information about soil contamination. We present a case study with 76 soil samples taken from a site of 15 square $\mathrm{km}$ in order to assess the usability of information gleaned from sparse data. The soil was contaminated with cadmium predominantly as a result of airborne emissions from a metal smelter. The spatial interpolation applies lognormal anisotropic kriging and conditional simulation for log-transformed data. The uncertainty of cadmium concentration acquired through data sampling, sample preparation, analytical measurement, and interpolation is factor 2 within $68.3 \%$ confidence. Uncertainty predominantly results from the spatial interpolation necessitated by low sampling density and spatial heterogeneity. The interpolation data are shown in maps presenting likelihoods of exceeding threshold values as a result of a lognormal probability distribution. Although the results are not deterministic, this procedure yields a quantified and transparent estimation of the contamination, which can be used to delineate areas for soil improvement, remediation, or restricted area use, based on the decision-makers' probability safety requirement.
Land-use management is challenging for the planning departments of both local and regional governments, especially where land use is extensive and contaminants are widespread (Roe and van Eeten 2001). Low concentrations of pollutants have long-term impacts, e.g., on soil fertility in the case of soil contaminants (Grunewald 1997; Gysi and others 1991). The impact of contaminants contributes to a shortage of usable land and consequently to competition of interest among different land uses. As a result, the market value of usable land may change and thus affect sustainable land-use management as Prato (2000) demonstrated.

We present a case study involving a location with cadmium-contaminated soil. For a large part of the area considered, soil measurements show contamination levels above the guide value, but below the remediation value as outlined in the Swiss Ordinance Relating to Pollutants in Soil (VBBo 1998) (Tables 1 and 2). If the guide value is exceeded, remediation of the soil may be considered appropriate where contamination of groundwater, crops, or soil fertility could be endan-

KEY WORDS: Conditional simulation; Lognormal ordinary kriging; Uncertainty assessment; Probability of occurrence; Sparse data

Published online June 29, 2004.

*Author to whom correspondence should be addressed, email: schnabel@nsl.ethz.ch gered. However, in this case, there are no standards mandating a cleanup. According to Swiss Ordinance Relating to Pollutants in Soil (VBBo 1998) soil contamination levels between the guide value and remediation value indicate the necessity of a change in land use, for example, from food production to residential use. Such changes often provide a less expensive alternative to remediation. Remediation is only legally obligatory when the remediation value is exceeded. This legal situation shows that assessment of soil contamination is relevant for sustainable land management, even when the pollutants pose no risk to human health. Assessment of soil contamination for precautionary soil improvement is difficult, because of the lack of data and high degree of uncertainty from sparse data. Decisions on soil use change are difficult to substantiate. In order to evaluate the affected areas in a valid, reliable, and cost-effective way, a spatial interpolation that includes appropriate uncertainty information is required.

The common sources of uncertainty in spatial prediction are data sampling (sparseness and inaccuracy), the preparation and measurement of samples in the laboratory (Dubois and Schulin 1993, Muntau and others 2001), the spatial interpolation of the data (Goovaerts 2001, Meuli 1997), and subsequent modeling (Hendriks and others 2000, Keller and others 2001, 2002). Several geostatistical models address the amount of uncertainty from interpolation techniques (Barabas 
Table 1. Legal threshold values for remediation of cadmium in soil in Switzerland (VBBo 1998)

\begin{tabular}{ll}
\hline $\begin{array}{l}\text { Swiss Ordinance Relating to } \\
\text { Pollutants in Soil }\end{array}$ & $\begin{array}{l}\text { Cadmium total, } \\
\mathrm{HNO}_{3} \text { soluble } \\
(\mathrm{mg} / \mathrm{kg})\end{array}$ \\
\hline $\begin{array}{l}\text { Guide Value } \\
\text { Trigger Value }\end{array}$ & 0.8 \\
Use with probable oral intake & 10 \\
Use for food planting & 2 \\
Use for feed planting & 2 \\
Remediation Value & \\
Agriculture and horticulture & 30 \\
Gardening & 20 \\
Playgrounds & 20 \\
\hline
\end{tabular}

Table 2. Statistical properties of the data

\begin{tabular}{lll}
\hline Value & $\mathrm{Cd}(\mathrm{mg} / \mathrm{kg})$ & in $\mathrm{Cd}(\mathrm{mg} / \mathrm{kg})$ \\
\hline Count & 76 & 76 \\
Geometric mean & 0.93 & - \\
Arithmetic mean & 1.43 & -0.08 \\
Standard deviation & 2.69 & 0.80 \\
Variance & 7.26 & 0.64 \\
exp \{average $[\ln (\mathrm{Cd})]\}$ & 0.93 & - \\
exp \{stddev[ln $(\mathrm{Cd})]\}$ & 2.22 & - \\
Median & 0.86 & -0.16 \\
exp\{median $[\ln (\mathrm{Cd})]\}$ & 0.86 & - \\
Skewness & 7.36 & 0.78 \\
Kurtosis & 59.67 & 2.89 \\
Min & 0.12 & -2.12 \\
Max & 23.3 & 3.15 \\
\hline
\end{tabular}

and others 2001, Bouma and others 1996, von Steiger and others, 1996). Modeling uncertainty by means of stochastic simulation is also widely used (Gotway and Rutherford 1993, Pan 1997, Van Meirvenne 2001). For example, Goovaerts (2001) compared kriging-based estimation to simulation-based spatial estimation and concluded that simulation offers several advantages, the most important one being that it provides a model of spatially local uncertainty. In cases of lognormally distributed data, ordinary lognormal kriging is easy to implement and yields better results than other kriging methods (Papritz and Moyeed 1999, Saito and Goovaerts 2000). Other investigations applied indicator kriging (Van Meirvenne 2001, Webster and Oliver 2001) or disjunctive kriging (Papritz and Moyeed 1999, von Steiger and others 1996), because of the complications to estimating the local probability density function when applying a traditional backtransformation (Geovariances 1997, Webster and Oliver 2001, p. 19). Therefore, we follow the approach of Limpert and others (2001), who presented the uncertainty on the raw scale by means of the geometric mean, the multiplicative standard deviation, and consequently, the multiplicative confidence intervals for a multitude of lognormal-distributed data.

Thompson and Fearn (1990, p. 271) discuss the relation between sampling and cost of analysis as well as the quality of data appropriate for data assessment. They define fitness for purpose as "the property of data, produced by a measurement process, that enables a user of the data to make technically correct decisions for a stated purpose." The decision whether or not the information supplied by the available data and its degree of uncertainty are useful depends on the purpose for which the data will be used. Decision-makers have to judge the appropriateness of using uncertainties as a substantive base for their decision (Ramsey and others 1998, Thompson 1995). It is the decision and its consequences that matter, rather than the accuracy of the prediction (Goovaerts and Meirvenne 2001). Thus, the main objective of this study is to analyze the usability of the information given by spatial interpolation of few measurements, combined with probabilistic reasoning based on sparse data for the case of Dornach (Canton Solothurn, Switzerland). The following questions will be addressed:

- What kind of spatial prediction is suitable when distant, irregularly distributed measurements are analyzed for environmental management purposes?

- How can the uncertainty in an interpolation be best assessed and presented?

- What possibilities and limitations are posed by applying the interpolation method and its resulting uncertainty for practical planning purpose?

\section{Data}

We present a case study from Switzerland where 76 soil samples were taken in an area of 15 square kilometers. Each was a composite sample from topsoil $(20 \mathrm{~cm}$ depth) within a range of 10 square meters (Wirz and Winistörfer 1987). Soil samples were taken without a specific sample design, and the sites were more or less randomly distributed. An attempt was made to cover the supposed area of contamination (Figure 1) and take local circumstances into account.

The total heavy metal content of the soil was determined in a $2 \mathrm{M} \mathrm{HNO}_{3}$ extract following the Swiss Ordinance Relating to Pollutants in Soil (VBBo 1998) and measured with a atom adsorption spectrometer (AAS) using the flame-AAS method.

The data analysis in Table 2 reveals that the distribution of heavy metal measurements is highly skewed 


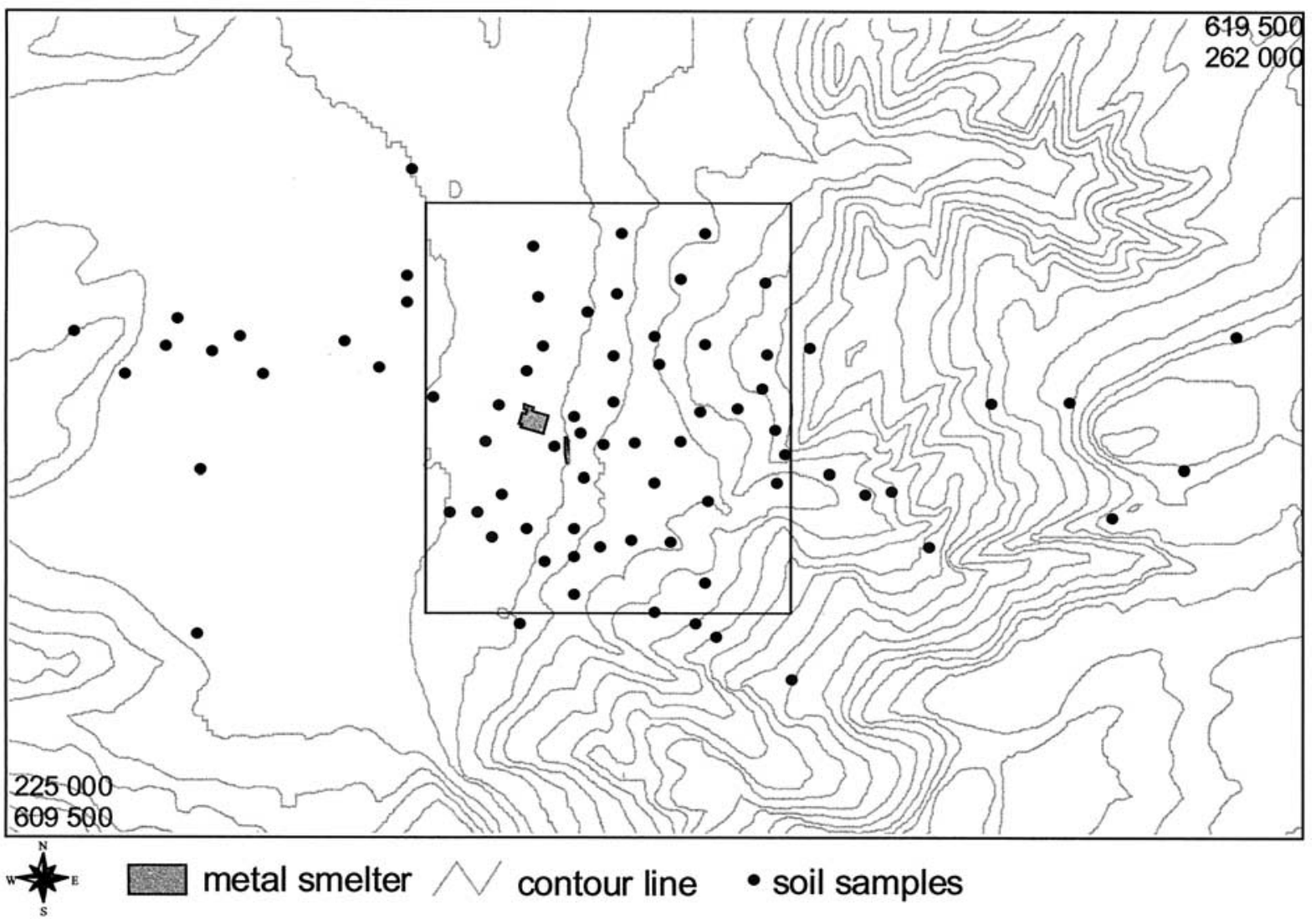

Figure 1. Spatial distribution of sampling points in Dornach (Canton Solothurn, Switzerland).

Table 3. Test of normality with a one-sample Kolmogorov-Smirnov test for the logtransformed data ${ }^{a}$

\begin{tabular}{llll}
\hline & $\mathrm{Cd}(\mathrm{mg} / \mathrm{kg})$ & $\operatorname{Ln}(\mathrm{Cd})(\mathrm{mg} / \mathrm{kg})$ & $\mathrm{Ln}(\mathrm{Cd})(\mathrm{mg} / \mathrm{kg})^{\mathrm{a}}$ \\
\hline $\mathrm{N}$ & 76 & 76 & 29 \\
Normal parameters & & & -0.06 \\
\hline Mean & 1.43 & -0.08 & 0.98 \\
$\mathrm{SD}$ & 2.69 & 0.80 & \\
Most Extreme Differences & & & 0.13 \\
\hline Absolute & 0.31 & 0.11 & 0.13 \\
$\quad$ Positive & 0.30 & -0.06 & 0.13 \\
Negative & -0.31 & 0.94 & 0.68 \\
Kolmogorov-Smirnov Z & 2.74 & 0.35 & 0.74 \\
Asymp. Sig. (2-tailed) & 0.00 & & \\
\hline
\end{tabular}

${ }^{\mathrm{a} A}$ subsample of spatial independent data fulfill the assumption of independency (test distribution is normal, mean and standard deviation are calculated from data).

(skewness 7.36). This also shows the difference between the arithmetic mean $(1.43 \mathrm{mg} / \mathrm{kg})$ and the geometric mean $(0.93 \mathrm{mg} / \mathrm{kg})$ of the raw data. For such data, logarithmic transformation may be appropriate before interpolation. The statistics from a Kolmogorov-Smirnov test show that the logarithmically transformed data follow a normal distribution $(P \geq 0.35$, Table 3$)$. Be- cause the test presumes independency of the observations, a random set from the data, chosen with the most possible distance from every other measurement point, was also tested and accepted $(P=0.74$, Table 3$)$.

Cadmium was emitted from a metal smelter during the past century. Today the pollutant can be found on the west side of Dornach (Figure 1), a result of the 

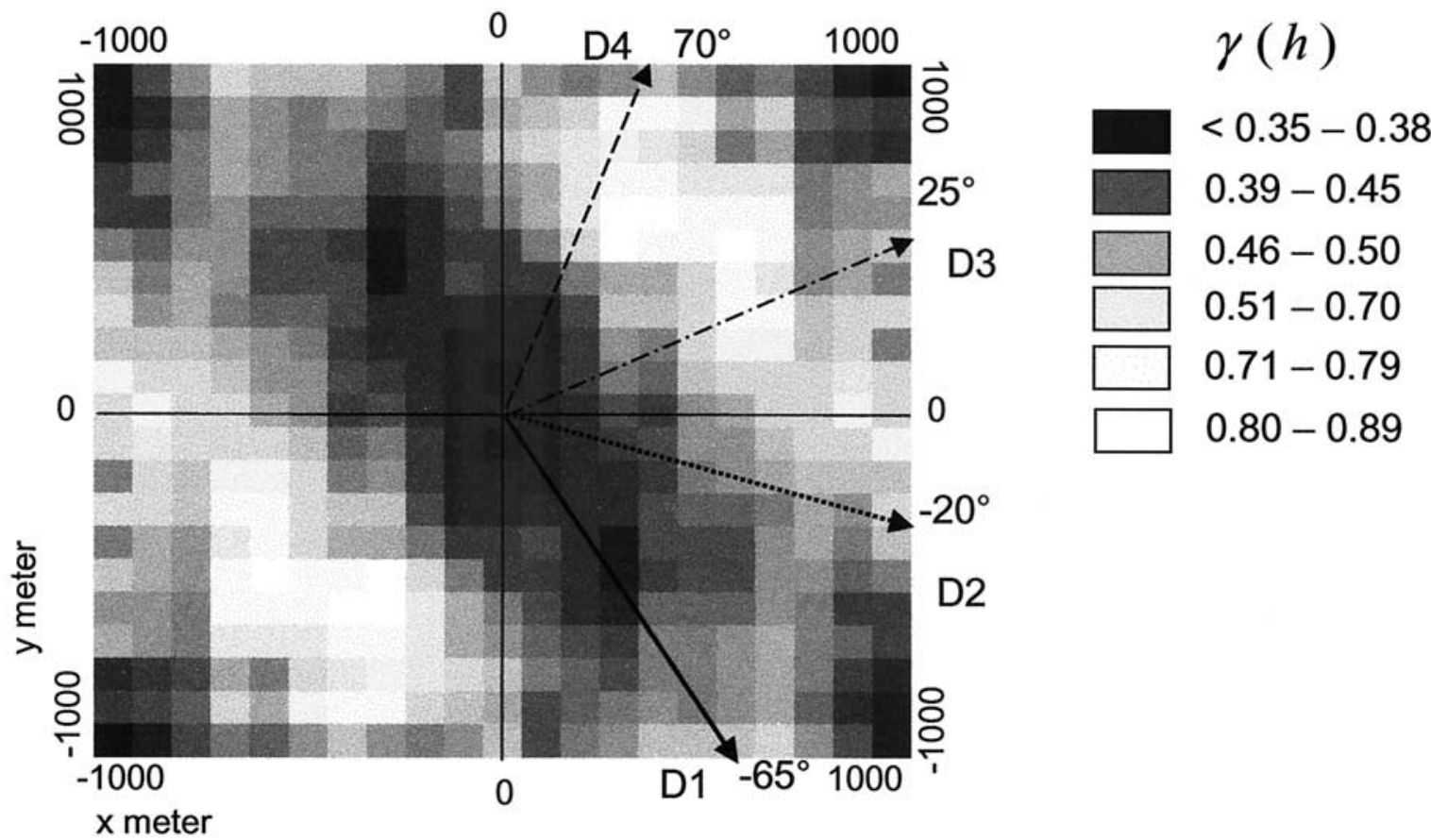

Figure 2. Variogram map of the logarithmically transformed cadmium data. Each grid cell shows the semivarince of the lag vector $(x, y)$. D1-D4 indicate the direction of the anisotropic variograms.

west-to-east dominant wind direction (Schweizerische Meteorologische Anstalt 1982-91) and the northwest facing slope on which the community of Dornach was built (Hesske and others 1998). In addition to the airborne contamination, the cadmium content in parent material is about the Swiss average of $0.3 \mathrm{mg} / \mathrm{km}$ of soil (Tuchschmid 1995, Keller 2001).

Geiger and Schulin (1995) found high variability ( $N$ $=50$, average $=4.38 \mathrm{mg} / \mathrm{kg}$, variance $0.72(\mathrm{mg} / \mathrm{kg})^{2}$, $\min =2.37 \mathrm{mg} / \mathrm{kg}, \max =5.92 \mathrm{mg} / \mathrm{kg}$ ) on a $40 \mathrm{~m}$ transect in the same area. Soil parameters and contaminants tend to behave randomly on the small scale (Webster 2000). Thus, for this case study, it was necessary to take the variability of the data on a scale of a few tens of meters into account when we analyzed it.

\section{Methods}

Within the framework of geostatistical analysis, the measured cadmium concentrations (see above) are assumed to be one realization of a stochastic process $\{Z(x): x \in D\}$ (Cressie 1993, Goovaerts 1997), where $D$ denotes the sample space for the investigated case study area of Dornach (Figure 1). Let $x_{1}, \ldots, x_{n}$ denote the data coordinates and $Z\left(x_{1}\right), \ldots, Z\left(x_{n}\right)$ the logarithms of the measured cadmium concentrations of the 76 measure- ments. Then, the difference $Z(x)-Z(x+h)$ with $x, x+$ $h \in D$ depends on the distance vector $h$ (Matheron 1963). This dependency is expressed by means of the semivariance $\gamma(h)$, which is defined as half the variance of concentration differences of all data pairs with the same distance $h$ (Journel 1989). The range $r-$ the spatial dependency - indicates the maximum distance between sites, beyond which concentrations are considered to be uncorrelated. Properties and characteristics of this function are discussed in geostatistical textbooks (e.g., Cressie 1993, pp. 58ff).

\section{Analysis of spatial dependency}

The spatial dependency of the cadmium concentrations is empirically investigated using standard geostatistical software (Geovariances 1997). The investigation includes the (supposed) total area of contamination.

A variogram map (see Figure 2) of the logarithmically transformed cadmium data shows an empirical semivariance function, which depends on the length and direction of distance vector $h$. It shows that in the southeast direction the range is larger than in other directions. This indicates that an anisotropic semivariance should be considered. For the variogram model we used a spherical function (Figure 3), which is expressed as (equation 1): 
Figure 3. Anisotropic variograms in the directions D1-D4; their ranges are $900 \mathrm{~m}$ to $500 \mathrm{~m}$, the nugget effect is $0.13(\mathrm{mg} / \mathrm{kg})^{2}$, and the sill is $0.53(\mathrm{mg} / \mathrm{kg})^{2}$. Number of pairs and lag value for each lag are shown in the annotations.

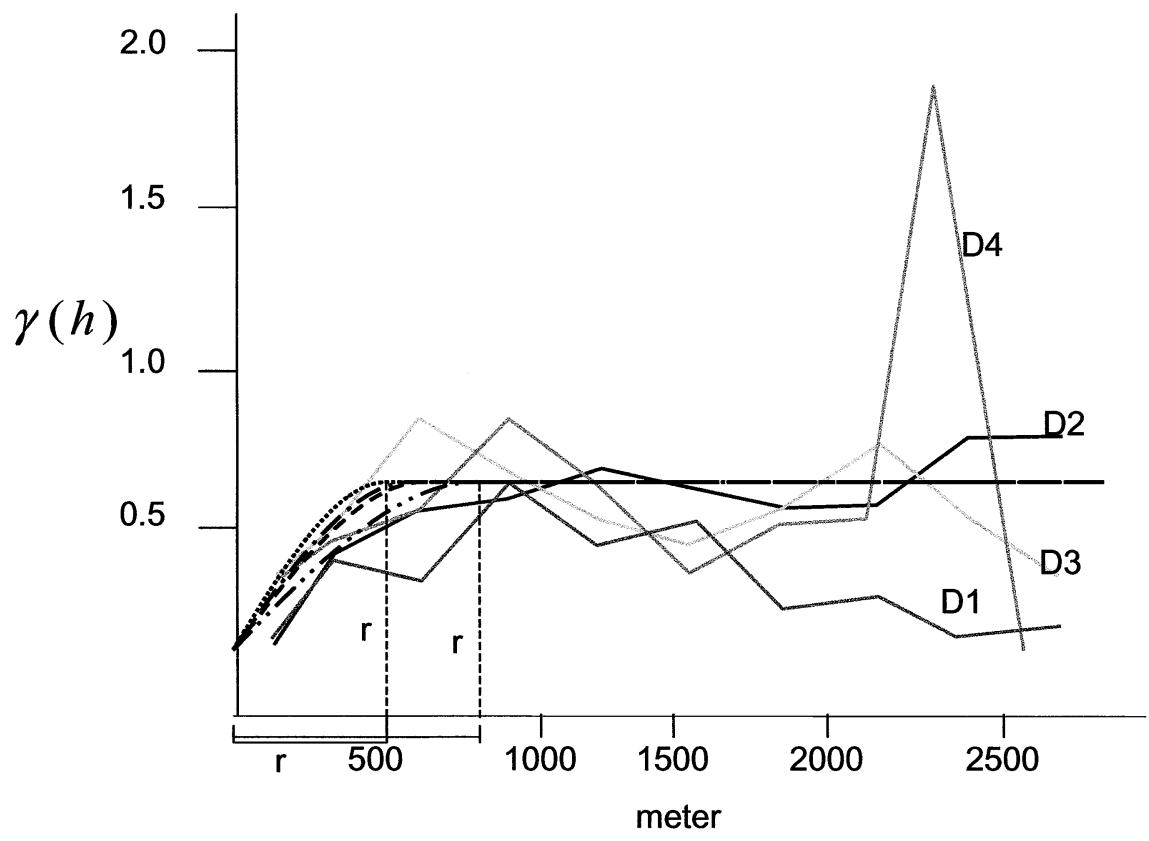

$\gamma(\mathrm{h}, \theta)=\mathrm{c}_{0}+\mathrm{c}_{1}\left\{\frac{3 \mathrm{~h}}{2 \Omega(\theta)}-\frac{1}{2}\left[\frac{\mathrm{h}}{\Omega(\theta)}\right]^{3}\right\}$ for $0<h$

$$
<\Omega(\theta)
$$

$\% \gamma(h, \theta)=c_{0}+c_{1}$ forh $\geq \Omega(\theta), \gamma(0)=0$ where $\gamma(h, \theta)$ is the semivariance dependent on $h$, (the lag, which is defined as the Euclidian distance between two points in two dimensions), and on $\theta$, the angle representing the direction of the lag. The term $\mathrm{c}_{0}$ is the nugget effect; $\mathrm{c}_{1}$, the sill; and $\Omega(\theta)=\left[\mathrm{A}^{2} \cos ^{2}(\theta-\alpha)+\mathrm{B}^{2} \sin ^{2}(\theta\right.$ $-\alpha)]^{\frac{1}{2}}$, which defines the geometric anisotropy by means of an ellipsoid with angle $\alpha$, the direction in which the continuity is greatest; $A$, the maximum diameter; and $B$, the minimum diameter, which is perpendicular to $A$ (Webster and Oliver 2001). This express the so-called geometric anisotropy, for which the range (but not the sill) depends on the direction. Referring to the variogram map, the direction $\alpha$ of the largest diameter is set to $-65^{\circ}\left(155^{\circ}\right.$ in geographical notation; see Figure 2). Other kinds of semivariance functions (like Gaussian or exponential) and zonal anisotropy are discussed by Journel and Huijbregts (1978) and Matheron (1963).

Further, for the analysis of spatial contamination pattern, trend models for the components of distance to the metal smelter $(d)$ and deviation from the dominant wind direction $(\Delta \theta)$ are used as suggested by Saito and Goovaerts (2001). Trend factors are fitted with five different regressions and residues are used to predict the spatial dependency. Hereafter the mean square error (MSE) from cross validation (Goovaerts 2001, Armstrong 1998) indicates the goodness of prediction with a trend.

\section{Ordinary Kriging}

The interpolation applies an ordinary kriging method, where the data are logarithmically transformed before kriging, and then transformed back afterwards. Lognormal ordinary kriging interpolates by means of a weighted average (equation 2):

$$
\mathrm{Z}^{*}\left(x_{0}\right)=\sum_{i=1}^{n} \lambda_{i} Z\left(x_{i}\right)
$$

where $Z *\left(x_{0}\right)$ is the estimated value at point $x_{0}, Z\left(x_{i}\right)$ is the measured value at $x_{i}$, and $\lambda_{i}$ are the weights (adding up to 1 ). Nearby measurements are considered to be more correlated to the estimation point and, therefore, carry a higher weight than more distant measurements. A moving (ellipsoidal) neighborhood is defined by the parameters of anisotropy, i.e., a rotation of $\alpha=-65^{\circ}$ and a range of $A=900 \mathrm{~m}$ (direction D1, D2) and $B=500 \mathrm{~m}$ (direction D3, D4). This distributes the weight of the sampling points along the preferred direction, thus emphasizing the local spatial structure of contamination.

The kriging variance $\sigma_{Z} i^{2}\left(x_{0}\right)$ is computed as the weighted sum of the estimation point $\left(x_{0}\right)$ and the measured points (Equation 3). The kriging variance is then 


$$
\sigma_{Z^{\prime}}^{2} \cdot\left(x_{0}\right)=\sum_{i=1}^{n} \lambda_{i} \gamma\left(x_{i}, x_{0}\right)+\psi\left(x_{0}\right)
$$

Where $\lambda\left(x_{i} x_{0}\right)$ is the semivariance between the data point $x_{i}$ and the estimation point $x_{0}$. The weights $\lambda_{i}$ are distributed in terms of the data model (see above) and under the requirement of unbiasedness. $\psi\left(x_{0}\right)$ is the Lagrange multiplier used for minimization of the kriging variance (Cressie 1993, Journel 1989). The kriging system is given in detail in the annotations.

After kriging, the lognormal estimates are transformed back to the original scale. Several back-transformations methods have been proposed (Cressie 1993, p. 136, Saito and Goovaerts 2000, Webster and Oliver 2001 , p. 180). We transformed the values back according to equation 4 :

$$
Z_{r}^{*}=\exp \left(Z^{*}+\frac{\sigma_{Z^{*}}^{2}}{2}\right)
$$

where $Z_{r}^{*}$ is the estimated value in the raw scale, $Z^{*}$ is the estimated value, and $\sigma^{Z}{ }_{Z} i$, is the kriging variance, all on the logarithmic scale. For the kriging variance the transformation (Limpert and others 2001, Stahel, 2000, p. 136) is (equation 5):

$$
\sigma_{Z_{i}^{*}}^{2}=m_{r} e^{S_{r}^{2}}\left(1-e^{-\sigma_{Z^{*}}^{2}}\right)
$$

where $m_{r}$ is the mean, $s_{r}^{2}$ is the dispersion variance of the raw variable, and $\sigma_{Z i}{ }^{2}$ is the kriging variance (on the log scale) (Geovariances 1997). For the statistical characterization of the interpolated data, we calculated the median of the raw variable given the mean $Z^{*}$ on the $\log$ scale as $Z_{r}^{M}(x)=\exp \left[Z^{*}(x)\right]$ (median of the raw variable) and the multiplicative standard deviation from the untransformed kriging variance $\sigma_{Z i}{ }^{2}$ on the $\log$ scale as $\sigma(x)=\exp \left[\sigma_{Z}^{\mathrm{m}}(x)\right]$ (Limpert and others 2001, Stahel, 2000, p. 136). Please note that $Z^{P}$ is the median (and not the mean) of the raw variable and that the multiplicative standard deviation (sometimes called the geometric standard deviation) is calculated as the exponential of the standard deviation $\sigma_{Z i}$ on the $\log$ scale (and not as the exponential of the variance on the $\log$ scale).

Geostatistical conditional simulation To characterize the small-scale variability without a smoothing effect, a random realization of a stochastic process is generated. The idea is to compute a multitude of such random realizations and characterize the distribution at each estimation point through the average and standard deviation. All calculations are conducted using the logarithmically transformed data.

The stochastic simulation was performed using the turning bands method (Matheron 1963, Tietje 1993), which is one of the two available methods [as sequential Gaussian simulation (Deutsch and Journel 1998) ]. The turning bands method simulates realizations of a onedimensional Gaussian process $[Y(t u): t \in R]$ along the $L$ lines $L_{1}, \ldots, L_{L}$ through the origin defined by the unit vectors $\bar{u}_{1}, \ldots, \bar{u}_{L}$. The lines all have the same arbitrary origin (Gotway 1994) and are uniformly distributed within the (in this case) 2-dimensional space. If $u_{1}, \ldots, u_{L}$ are unit vectors in the direction $L_{1}, \ldots, L_{L}$, the simulated value $Z_{s}(x), x \in D$, is an average of those values, which are generated at the orthogonal projection $t_{u i}(x)$ of the terminal point $x$ onto the line of direction $\left.\vec{u}_{i},\left\{Y_{u i}(x) * \vec{u}_{i}\right]: i=1, \ldots, L\right\}$. Finally, the generated value at point $x$ is (equation 6):

$$
Z_{s}(x)=\frac{1}{\sqrt{ } L_{i=1}} \sum^{L} Y\left[t_{u i}(x) \vec{u}_{i}\right]
$$

A detailed discussion of the method can be found in Gotway (1994) and Journel (1974). Conditioning the simulation means to force the simulated surface to pass through the measurements. Hence, the simulated value is obtained through the formula (Journel and Huijbregts 1978) (equation 7):

$$
Z_{c s}^{*}(x)=Z^{*}(x)+\left[Z_{s}(x)-Z_{s}^{*}(x)\right]
$$

where $Z^{*}(x)$ is the kriged value obtained from the data $Z\left(x_{i}\right)$, (measurements $\left.i=1, \ldots, n\right), Z_{s}(x)$ is the simulated value from equation 6 , and $Z_{s}^{*}(x)$ is a kriged value obtained from $Z_{s}\left(x_{i}\right)$ using the realizations at the coordinates of the measurements. The conditional simulation was conducted with 100 turning bands for each of 100 realizations at each gridpoint $x \in D$. A simulation postprocessing averages the results of simulations according to equation 7 for each grid node

$$
Z_{c s}^{\mu}(x)=\frac{1}{100} \sum_{i=1}^{100} Z_{c s}^{*}(x) .
$$

At each gridpoint $x \in D$ the mean is used to interpolate the cadmium concentration, and the standard deviation

$$
\sigma_{c s}^{*}(x)=\sqrt{\frac{1}{99} \sum_{i=1}^{100}\left[Z_{c s}^{*}(x)-Z_{c s}^{\mu}(x)\right]^{2}}
$$

is used for uncertainty assessment. Similar to the lognormal kriging method, the following equations are used for calculation of the median and the multiplicative standard deviation:

$$
Z_{c s}^{M}(x)=\exp \left[Z_{c s}^{*}(x)\right]
$$

which is median of conditional simulation of the raw variable and

$$
\sigma_{c s}(x)=\exp \left[\sigma_{c s}^{*}(x)\right]
$$


which is standard deviation of conditional simulation of the raw variable.

Uncertainty assessment To assess the overall uncertainty of the interpolated concentrations, we consider the following sources of error: soil sampling, sample preparation for analytical measurement, analytical measurement itself, and interpolation. One model for these sources of error is the sum of variances induced throughout the assessment. Following the approach of the Analytical Methods Committee (1995) and Ramsey and Argyraki (1997), we assume the uncertainty $U(x)$ (equation 12) as random field

$$
U(x)=\sigma_{\text {constant }}^{2}+V(x) \text { for all } x \in D
$$

which includes a constant part $\sigma^{2}$ constant and a spatially variable part $V(x) . V(x)$ indicates the error due to interpolation and $\sigma^{2}$ constant indicates the uncertainty induced by soil sampling and measuring. The latter is considered to be the sum of the uncertainties of soil sampling (sampling pattern, density, composite, or spot sample), preparation of the soil sample (fragment removal, drying, grinding, sieving, splitting), and measurement of the cadmium content [flame-atom-spectrometer (AAS)] itself (Muntau and others 2001, Theocharopoulos and others 2001) (equation 13).

$\sigma_{\text {constant }}^{2}=\sigma_{\text {sampling }}^{2}+\sigma_{\text {samplingpreparation }}^{2}+\sigma_{\text {measurement }}^{2}$

The project "European methods in soil sampling" (CEEM) (Desaules and others 2001, Wagner and others 2001a) has evaluated the sources of uncertainty in soil pollutants assessment. It demonstrated that sampling and/or sampling preparation are the main sources of uncertainty, to the degree of which depends on the element analyzed and its concentration level (Wagner and others 2001b). Moreover, the investigation emphasized the deviation from sampling being higher than the analytical deviations. This is especially true for cadmium. From the results of the CEEM project, we derived an uncertainty of $0.3 \mathrm{mg} / \mathrm{kg}$ for sampling and sampling posttreatment for the constant part of the overall uncertainty $\left(\sigma^{2}\right.$ constant $)$ (Wagner and others 2001b, p. 87). This uncertainty might also be caused by the use of different sampling techniques (with variations in sampling depth, sieving, etc.), the presence of small-scale heterogeneity [about 40\% (see Wagner and others 2001b, p. 92)], and diversity of conditions associated with type of land use [variation coefficients of 8.1 $\%, 7.2 \%$, and $2.7 \%$ for forest, agriculture, and grassland use (Desaules and others 2001)]. Von Holst (1997) claims that sampling itself causes the highest degree of error followed by sampling preparation. Wächter (1997) even infers that the error of the mea- surement instruments is negligible relative to the high error influence of sampling.

Concerning the spatially variable part of the uncertainty [ $V(x)$, equation 8], the geostatistical theory (Armstrong 1998, Webster and Oliver 2001) states that the kriging variance is zero at measurement points and minimized (equations 2 and 3 ) between the sampling points. The magnitude of the kriging variance, therefore, depends on the distribution of the sampling points (note that the kriging characteristics - neighborhoods, anisotropy, the support, etc. - have to be set carefully). Because the sampling in the investigated area is sparse, large parts of the investigated area are expected to show a high kriging variance. The maximum of the kriging variance is related to the sill of the variogram and hence depends on the overall variance of the data (see above).

Finally, the overall uncertainty is calculated as $U(x)=\exp \left(\operatorname{In} 1.35+1 n \sigma_{v(x)}\right)$, which is used to estimate the spatially distributed uncertainty. Due to the geometric distribution (and hence the multiplicative confidence intervals) of the results, it is called the uncertainty factor throughout the text. In conclusion, the probability of exceeding a threshold of concentration $C$ is estimated by solving equation 14 :

$$
P\left(Z^{*}>C\right)=1-\phi\left[\left(\ln C-Z_{\log } *\right) / \sigma_{\mathrm{u}}(x)\right]
$$

for the probability $p_{x}$ of the standard normal distribution $\phi$.

\section{Results}

\section{Spatial Estimation}

The estimation of the spatial distribution of the cadmium concentration relies on the geostatistical analysis of the data. The trend analysis reveals no significant spatial trend. Besides a linear trend (Webster and Oliver 2001), the distance to the metal smelter and/or the main wind direction is additionally computed as regression parameters (Saito and Goovaerts 2001). Residues from regression are used for kriging and cross validation. Table 4 shows the mean square error of prediction with these trends compared to ordinary kriging without a trend. The results of Table 4 justify a spatial prediction without a trend in the investigated area.

Spherical models are suitable for both empirical variograms (Table 5, equation 1, and the isotropic spherical function is given in the annotations). In both cases, the sill approximately equals the data variance. The anisotropic and isotropic variograms on the log scale are shown in Figures 3 and 4. For the interpola- 
Table 4. Mean square error from cross validation for five different trend models and ordinary kriging (isotropic variogram) for 76 data points

\begin{tabular}{llll}
\hline & & & \multicolumn{2}{c}{ Model parameter } \\
\cline { 3 - 4 } Trend models & Mean square error & Nugget $\left[(\mathrm{mg} / \mathrm{kg})^{2}\right]$ & 0.10 \\
\hline$t_{0}=a_{0}+a_{1} x+a_{2} y$ & 0.48 & 666 & 0.14 \\
$t_{1}=a_{O}+a_{1} \ln (d)$ & 0.55 & 631 & 0.10 \\
$t_{2}=a_{O}+a_{1} \ln (d)+a_{2} \Delta \theta$ & 0.50 & 737 & 0.12 \\
$t_{3}=a_{O}+a_{1}(\ln (d) * \Delta \theta)$ & 0.53 & 597 & 0.23 \\
$t_{4}=a_{O}+a_{1} \Delta \theta+a_{2}(\ln (d) * \Delta \theta)$ & 0.46 & 696 & 0.30 \\
Ordinary kriging & 0.50 & 813 & \\
\hline
\end{tabular}

${ }^{a}(d)$ denotes the distance to the metal smelter and $(\Delta \theta)$ is the deviation of wind direction from west to east, $x, y$ are data coordinates. All models are calculated in accordance to Saito and Goovaerts (2001). Models of spatial dependency are derived from the residues of regression.

Table 5. Geostatistical properties of the variograms, all data shown on log-scale

\begin{tabular}{lll}
\hline & Isotropic variogram & Anisotropic variogram \\
\hline Model & spherical & spherical \\
Direction & omnidirectional & four directions, D1-D4 \\
Range & $813 \mathrm{~m}$ & $-65^{\circ}=900 \mathrm{~m},-20^{\circ},+20^{\circ},+70^{\circ}=500 \mathrm{~m}$ \\
Nugget effect & $0.297(\mathrm{mg} / \mathrm{kg})^{2}$ & $0.125(\mathrm{mg} / \mathrm{kg})^{2}$ \\
Sill & $0.332(\mathrm{mg} / \mathrm{kg})^{2}$ & $0.528(\mathrm{mg} / \mathrm{kg})^{2}$ \\
\hline
\end{tabular}

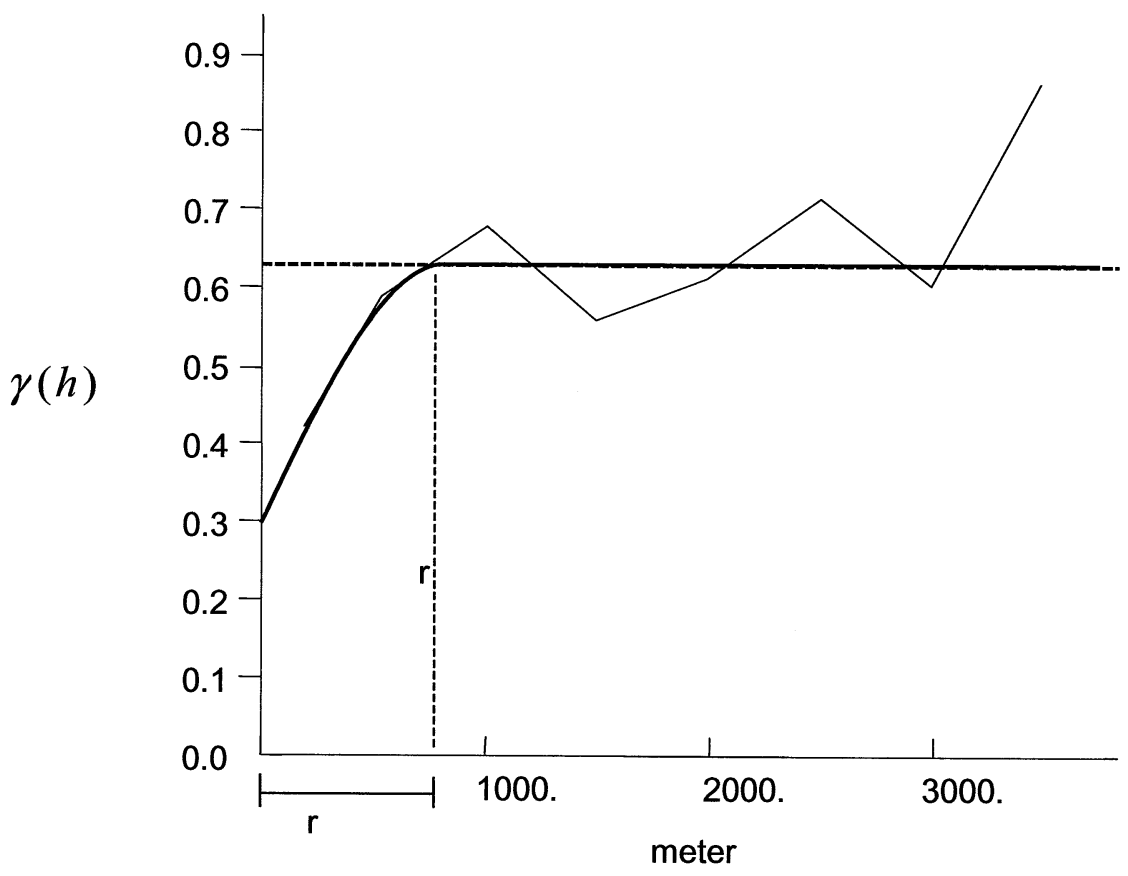

Figure 4. Isotropic variogram with a range of $813 \mathrm{~m}$, a nugget effect of $0.297(\mathrm{mg} / \mathrm{kg})^{2}$, and a sill of 0.332 $(\mathrm{mg} / \mathrm{kg})^{2}$. tion of cadmium, we use the anisotropic model displayed in Figure 3, because the variability of the cadmium contents depend on direction, as shown in the variogram map in Figure 2. The range is from $500 \mathrm{~m}$ to $900 \mathrm{~m}$, encompassing the range of the isotropic model. The anisotropic model is computed for lag classes of
$230 \mathrm{~m}$ and is discontinuous near the origin showing a nugget effect of $0.125(\mathrm{mg} / \mathrm{kg})^{2}$ (log scale).

The interpolated cadmium concentrations are displayed in Figure 5, which is a cutout of the interpolated area. The statistical properties of the interpolations (isotropic and anisotropic) and the 


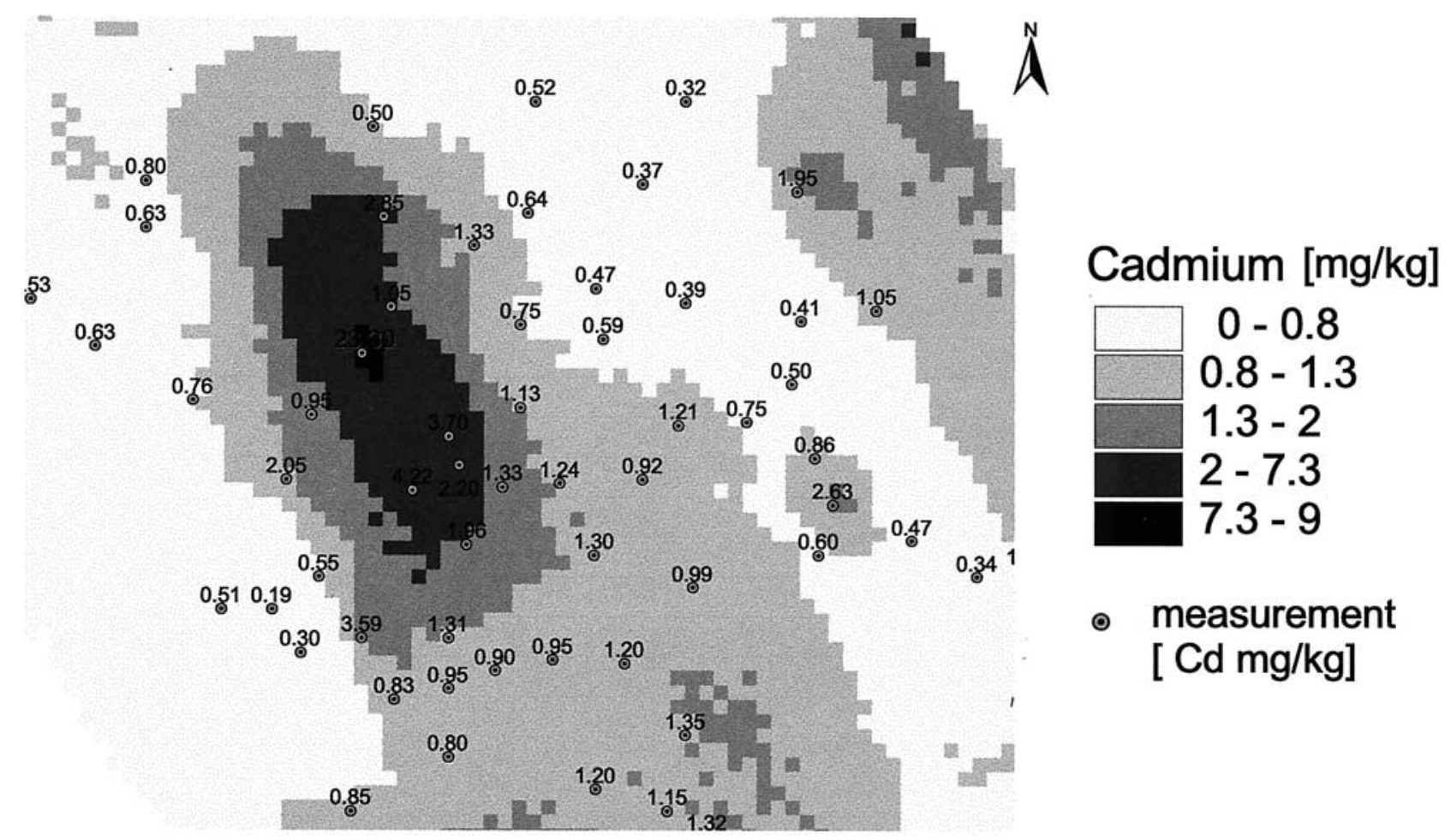

Figure 5. Spatial distribution of cadmium concentrations in topsoil after conditional simulation. The median of 100 realizations on the raw scale $\left[Z_{c s}^{M}\right]$ is displayed, taken only from the core area indicated in Figure 1.

Table 6. Statistical properties of the interpolations (isotropic and anisotropic) and the conditional simulation

\begin{tabular}{lllll}
\hline & Data & $\begin{array}{l}\text { Isotropic } \\
\text { estimation }\end{array}$ & $\begin{array}{l}\text { Anisotropic } \\
\text { estimation }\end{array}$ & $\begin{array}{l}\text { Conditional } \\
\text { simulation }\end{array}$ \\
\hline Counts & 76 & 11,878 & 10,802 & 10,802 \\
Geometric mean $\left[e^{\mu} \mathrm{mg} / \mathrm{kg}\right]$ & 0.93 & 1.05 & 1.08 & 1.09 \\
Standard deviation $\left[e^{\mu} \mathrm{mg} / \mathrm{kg}\right]$ & 2.22 & 2.33 & 2.27 & 2.33 \\
Minimum $[\mathrm{mg} / \mathrm{kg}]$ & 0.12 & 0.12 & 0.12 & 0.14 \\
Maximum $[\mathrm{mg} / \mathrm{kg}]$ & 23.3 & 4.36 & 8.81 & 9.03 \\
\hline
\end{tabular}

conditional simulation (anisotropic) are shown in Table 6. Differences between kriging of cadmium with isotropic and anisotropic variograms mainly results from their different nugget effects. The larger nugget effect leads to a smoother isotropic kriging interpolation (Webster and Oliver 2001) with less variance and an underestimation of cadmium concentrations.

The statistical properties of the anisotropic interpolation (Table 7) have been calculated for the area indicated to be the core area in Figure 1.

Uncertainty assessment The uncertainty of factor 2 (two times the estimate by multiplicative standard deviation) - postulated by the Analytical Methods Com- mittee (1995), Ramsey and Argyraki (1997), as well as Fresenius and others (1995) - can only be estimated at a probability of $68.3 \%$, whereas the demand of $p_{x}=$ $97.5 \%$ accuracy leads to an uncertainty factor of about 4.2. The uncertainty only decreases in the vicinity of the measurements.

The rationale of the spatially variable part $V(x)$ of the overall uncertainty is illustrated by Figure 6, which shows a north-south transection of Dornach. A single realization of the conditional simulation demonstrates considerable variability and randomly high cadmium concentrations.

As can be seen from Figure 6, in reality some cadmium concentrations beyond the $68.3 \%$ confidence 
Table 7. Statistical properties of the interpolation for the core area of pollution (indicated in Figure 1) and the total area of pollution

\begin{tabular}{|c|c|c|c|c|}
\hline \multirow[b]{2}{*}{ Anisotropic modeling } & \multicolumn{2}{|l|}{ Core area } & \multicolumn{2}{|l|}{ Total area } \\
\hline & $\begin{array}{l}\text { Cadmium } \\
\text { estimated }\end{array}$ & $\begin{array}{l}\text { Cadmium } \\
\text { simulated }\end{array}$ & $\begin{array}{l}\text { Cadmium } \\
\text { estimated }\end{array}$ & $\begin{array}{l}\text { Cadmium } \\
\text { simulated }\end{array}$ \\
\hline Counts & 3870 & 3870 & 10802 & 10802 \\
\hline Geometric mean $\left[e^{\mu} \mathrm{mg} / \mathrm{kg}\right]$ & 1.03 & 1.03 & 1.08 & 1.09 \\
\hline Standard deviation $\left[e^{\mu} \mathrm{mg} / \mathrm{kg}\right]$ & 1.95 & 1.97 & 2.27 & 2.33 \\
\hline Minimum $[\mathrm{mg} / \mathrm{kg}]$ & 0.28 & 0.28 & 0.12 & 0.14 \\
\hline Maximum $[\mathrm{mg} / \mathrm{kg}]$ & 8.81 & 9.03 & 8.81 & 9.03 \\
\hline
\end{tabular}

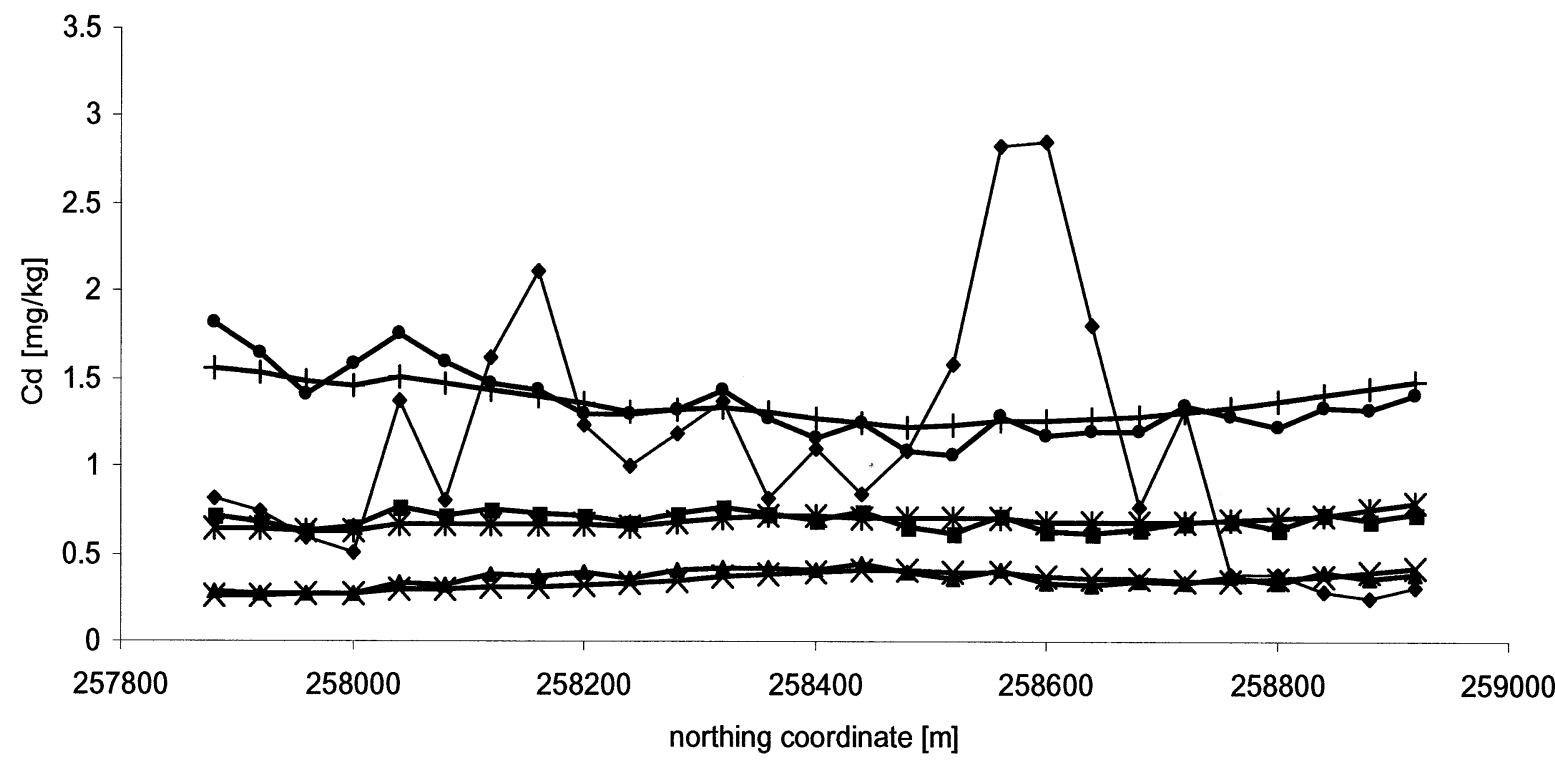

\begin{tabular}{ll|}
$\rightarrow-$ conditional simulation $50 \%$ percentile & $\rightarrow$ conditional simulation $84 \%$ percentile \\
$\rightarrow$ conditional simulation $16 \%$ percentile & $*$ lognormal kriging $50 \%$ percentile \\
+ - lognormal kriging $84 \%$ percentile & $*$ lognormal kriging $16 \%$ percentile \\
$\rightarrow-$ singular realization & \\
\hline
\end{tabular}

Figure 6. A south-north transection with the results of one singular realization and some percentiles of the conditional simulation and lognormal kriging. The 50th percentiles are estimated by taking the exponential of the mean values on the logarithmic scale. The other percentiles are calculated as the exponential of the percentiles on the logarithmic $\operatorname{scale} \exp \left[Z_{l o g}{ }^{*}\right.$ $\left.(x) \pm \phi(p) \sigma_{\log }(x)\right]$, with the 16 th and 84 th percentiles of the normal distribution $\phi(16 \%)=-1$ and $\phi(84 \%)=1$.

interval of the interpolation and simulation could occur. The results for the spatially variable part are indicated in Table 7 as is the geometric standard deviation $\mathrm{e}^{\mu} \mathrm{mg} / \mathrm{kg}$.

\section{Relevance for Decisions on Soil Remediation}

To come to any decision, the results of the kriging interpolation and the uncertainty assessment have to be in accordance with the standards set out in the Swiss
Ordinance Relating to Pollutants in Soil (VBBo 1998) (Table 1). This document contains the three threshold values associated with a long-term fertility goal (guide value), the concentration beyond which a more detailed investigation is required (trigger value), and the concentration beyond which a remediation is prescribed (remediation value).

Figure 7 presents the probability of exceeding $2 \mathrm{mg}$ cadmium per $\mathrm{kg}$ soil (trigger value for food and feed 


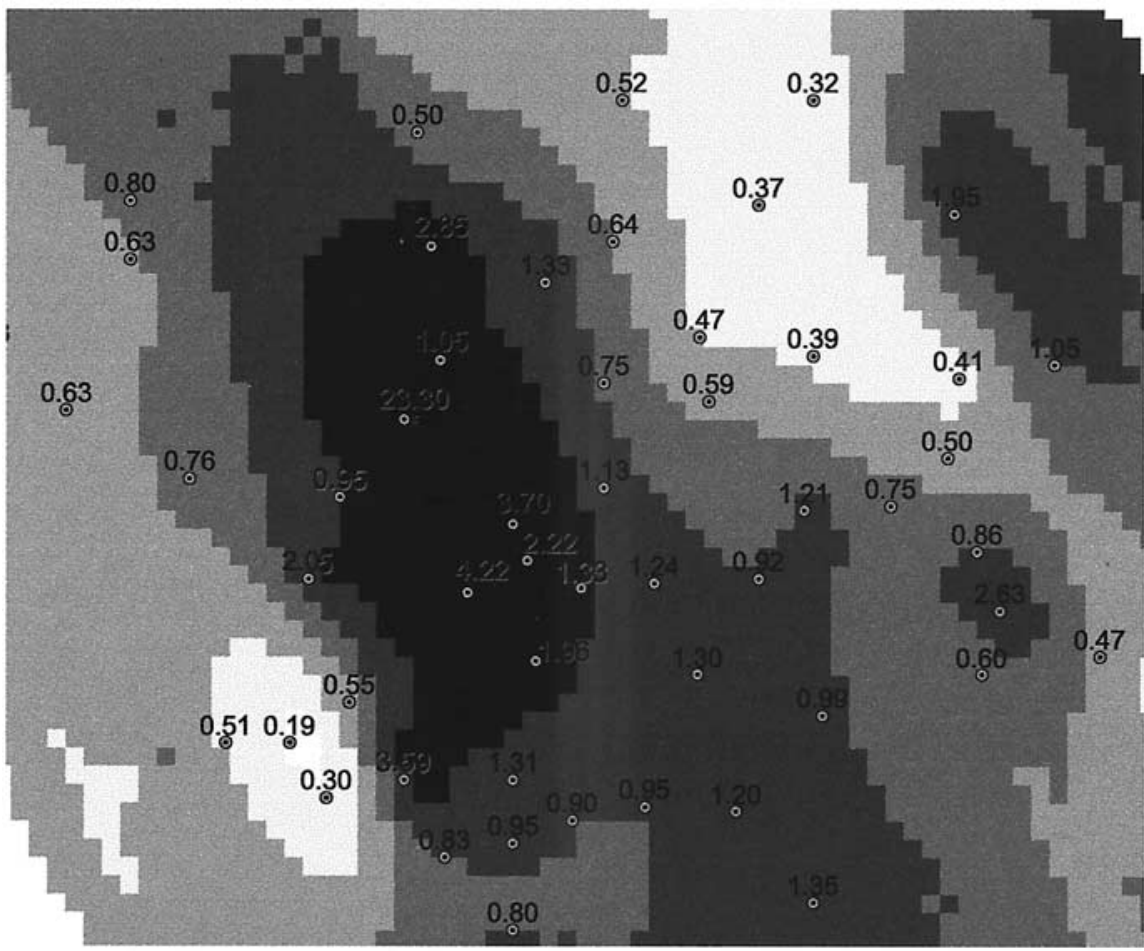

$\bigwedge^{N}$

Probability [\%]

$0-10$

$10-30$

$30-50$

$50-70$

$70-90$

$90-100$

$\odot$ measurement [ Cd mg/kg]

Figure 7. Map of the likelihood of exceeding the threshold value $C=2 \mathrm{mg} / \mathrm{kg}$.

planting). Clearly, the probability of any other threshold value can be presented. In practice, decision-makers have to agree on a probability statement that they consider reliable and safe enough for the specific case. Figure 6 shows one randomly chosen realization out of a total of 100 realizations that determine the simulated value. As can be seen, some local cadmium concentrations at this point exceed the 84th percentile of the prediction. Presentations, as the one demonstrated in Figure 6, facilitate understanding of the meaning and consequences of the results, which are phrased as "there is a $16 \%$ likelihood that a specific cadmium concentration will be exceeded". In addition, it is possible to delineate corresponding areas, which may be subjected to further investigations (e.g., additional measurements). A combination of the spatially distributed probability of occurrence with other data of a geographic information system (GIS), such as land use classifications, might lead to a valuable decision. However, if a high degree of reliability and confidence is required (e.g., $95 \%$ ) and the costs of soil treatment are very high, Figure 7 suggests that further measurements should be collected. In general, knowledge about the probability of exceeding legal threshold values helps to become aware of necessary actions that have to be taken in sustainable soil im- provement - depending on the decision-makers' risk level. For the case considered in this study, the following conclusions became evident from the interpolation and the uncertainty assessment:

- cadmium contamination above legal remediation value (for all kind of uses) is not likely (even with a probability below $50 \%$ ) on any side;

- a small area is contaminated above trigger value with a probability of more than $90 \%$;

- cadmium contamination above guide value is widespread with more than $50 \%$ probability;

- high probabilities for cadmium contamination above $0.8 \mathrm{mg} / \mathrm{kg}$ are delineated mainly around the emission source; and

- Only a small domain of the case area is not contaminated above the guide value of Swiss Ordinance related to Soil (VBBo 1998)

Since the contamination from sources such as sewage sludge or fertilizer is ongoing (Keller and others 2001), decision-makers should also bear in mind that the cadmium concentration might still be accumulating and any kind of soil improvement might help to sustain the multi-functional use of soil (Bouma 2002). 


\section{Conclusion}

The case study shows that even sparse data are suitable for an assessment of contaminated land. In our case we state an uncertainty factor of 2 with $68.3 \%$ accuracy and we acknowledge statements such as "The probability that the soil contamination at this point exceeds $2 \mathrm{mg}$ cadmium per $\mathrm{kg}$ soil is less than $40 \%$ ". We infer from the preceding analysis that statements of this kind can be given in a reliable way.

For the spatial interpolation of the cadmium concentrations, a lognormal ordinary kriging (Papritz and Moyeed 1999, Matheron 1963) and a conditional simulation (Goovaerts 2000, Journel 1974) were applied. The ordinary kriging was improved by the application of an anisotropic variogram. The anisotropic variogram shows varying distances of autocorrelation in different directions. Several two dimensional stochastic realizations were produced and a conditional simulation was applied to analyze the local variability. The conditional simulation (as the stochastic realizations are forced to hit the measured data) also yielded an estimation of the local uncertainty. A logarithmic transformation of the data and a back-transformation after interpolation according to Limpert and others (2001) was used to obtain the geometric mean and the multiplicative standard deviation. The geometric distribution was used to obtain the percentiles of the probability density function and to predict the conditional cumulative density function including the uncertainty. With this approach, the uncertainties involved in the interpolation are appropriately estimated. Hence, this procedure can be applied for uncertainty assessment of lognormally and spatially distributed data.

The uncertainty assessment exemplifies that the main part of the overall uncertainty is due to the sparseness of the data that underlies the spatial interpolation. The second important uncertainty is due to the sampling and sample preparation. Because corresponding data are hard to obtain (see, e.g., CEEM Project; Wagner and others 2001b), we roughly estimated this as 35 $\%$ of the estimated cadmium concentration using quantitative (von Holst 1997, Wächter 1997, Wagner and others 2001b) and qualitative results (Ramsey 1998, Tiktak and others 1999) as a reference. For the purpose of this investigation, other sources of uncertainty, such as the analytical measurement have been determined to be negligible. In conclusion, the resulting overall uncertainty is suitable to identify regions with a high risk of contamination. The interpolation combined with the uncertainty assessment is sufficiently reliable to delineate potentially contaminated sites pictured in "maps of probability of occurrence."
Table 8. Number of pairs and semivariances for single lags of the variogram calculated in Equation 1 and shown in Figure 3

\begin{tabular}{|c|c|c|c|c|c|c|c|c|}
\hline & \multicolumn{4}{|c|}{ Number of pairs } & \multicolumn{4}{|c|}{ Value $(\mathrm{mg} / \mathrm{kg})^{2}$} \\
\hline & D1 & D2 & D3 & D4 & D1 & D2 & D3 & D4 \\
\hline Lag 1 & 28 & 35 & 31 & 31 & 0.38 & 0.34 & 0.28 & 0.43 \\
\hline Lag 2 & 50 & 72 & 60 & 53 & 0.5 & 0.51 & 0.8 & 0.51 \\
\hline Lag 3 & 74 & 77 & 75 & 72 & 0.34 & 0.67 & 0.89 & 0.82 \\
\hline Lag 4 & 74 & 84 & 80 & 72 & 0.73 & 0.7 & 0.74 & 0.83 \\
\hline Lag 5 & 82 & 86 & 87 & 74 & 0.55 & 0.67 & 0.58 & 0.61 \\
\hline Lag 6 & 49 & 95 & 75 & 54 & 0.53 & 0.66 & 0.48 & 0.59 \\
\hline Lag 7 & 53 & 84 & 77 & 42 & 0.44 & 0.6 & 0.61 & 0.4 \\
\hline Lag 8 & 28 & 97 & 56 & 25 & 0.39 & 0.66 & 0.54 & 0.62 \\
\hline Lag 9 & 18 & 90 & 46 & 10 & 0.29 & 0.61 & 0.81 & 0.58 \\
\hline Lag 10 & 11 & 92 & 39 & 2 & 0.38 & 0.76 & 0.62 & 1.84 \\
\hline Lag 11 & 3 & 70 & 39 & 2 & 0.3 & 0.84 & 0.52 & 0.19 \\
\hline
\end{tabular}

\section{Acknowledgements}

The work reported in this paper was conducted in the context of the Integrated Project Soil of the Swiss Priority Program Environment. We are grateful to Martin Fritsch, who initiated the project and guided it until 2000, and to the colleagues at UNS and within the IP Soil for the helpful discussions. We also appreciate the comment of three anonymous reviewers. The project was funded by the Swiss National Science of Foundation (Project number 5001-44758) and the Swiss Federal Institute of Technology (Project number 0048-412609-5).

\section{Annotations}

Table 8 shows the number of pairs and semivariances for single lags of the variogram, calculated in equation (1) and shown in Figure 3.

The formal kriging system is:

$$
\begin{aligned}
& Z^{*}\left(x_{0}\right) \lambda= b \\
& Z^{*} \mathrm{x}_{0}=\left(\begin{array}{ccccc}
\gamma\left(x_{1}, x_{1}\right) & \gamma\left(x_{1}, x_{2}\right) & \ldots & \gamma\left(x_{1}, x_{N}\right) & 1 \\
\gamma\left(x_{2}, x_{1}\right) & \gamma\left(x_{2}, x_{2}\right) & \ldots & \gamma\left(x_{2}, x_{N}\right) & 1 \\
\vdots & \vdots & \ldots & \vdots & \vdots \\
\gamma\left(x_{N}, x_{1}\right) & \gamma\left(x_{N}, x_{N}\right) & \ldots & \gamma\left(x_{N}, x_{N}\right) & 1 \\
1 & 1 & \ldots & 1 & 0
\end{array}\right) \\
& \lambda=\left(\begin{array}{c}
\gamma \\
\lambda_{1} \\
\lambda_{2} \\
\vdots \\
\lambda_{N} \\
\psi\left(x_{0}\right)
\end{array}\right), \text { and b }=\left(\begin{array}{c}
\gamma\left(x_{1}, x_{0}\right) \\
\gamma\left(x_{2}, x_{0}\right) \\
\vdots \\
\gamma\left(x_{N}, x_{0}\right) \\
1
\end{array}\right)
\end{aligned}
$$

Spherical function calculated for Figure 5 and Table 5 and 6 : 


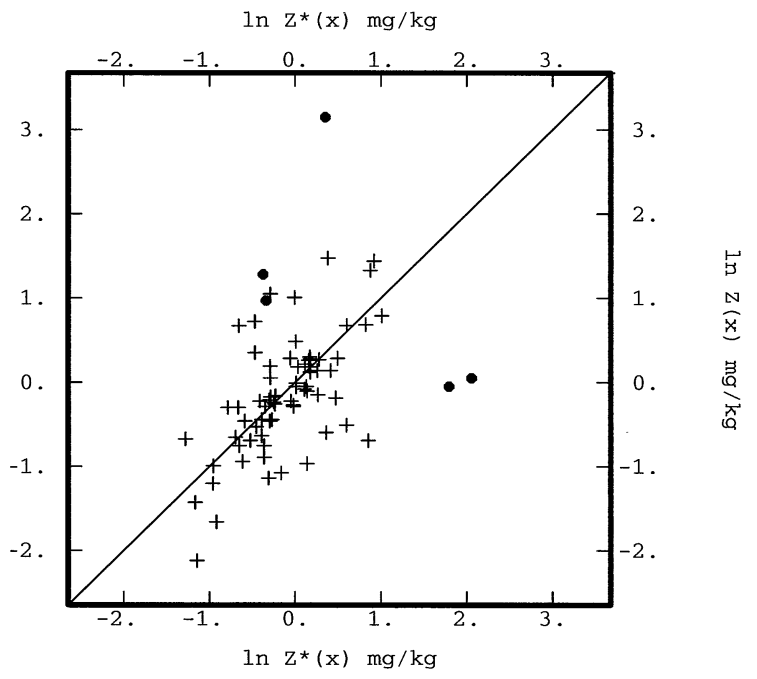

Figure 8. The accuracy plot for the variogram model calculated in equation 1 . Dots indicate outliers being outside the 99\% confidence limit of a normal distribution.

$$
\begin{aligned}
& \gamma(\mathrm{h})=\mathrm{c}_{0}+\mathrm{c}_{1}\left\{\frac{3 \mathrm{~h}}{2 a}-\frac{1}{2}\left(\frac{\mathrm{h}}{\mathrm{a}}\right)^{3}\right\}, \text { for } h \leq a \\
& \gamma(\mathrm{h})=\mathrm{c}_{0}+\mathrm{c}_{1} \text { for } h>a
\end{aligned}
$$

where $c_{0}$ is the nugget effect, $c_{1}$ is the sill, $h$ is the lag, and $a$ the range.

The accuracy plot for the variogram model calculated in equation 1 is given in Figure 8. Dots indicate outliers being outside the $99 \%$ confidence limit of a normal distribution.

\section{References}

Analytical Methods Committee 1995. Uncertainty of measurement: implications of its use in analytical science. Analyst 120:2303-2308.

Armstrong, M. 1998. Basic linear geostatistics. Springer, Berlin 146.

Barabas, N., P. Goovaerts, and P. Adriaens. 2001. Geostatistical assessment and validation of uncertainty for three-dimensional dioxin data from sediments in an estuarine river. Environmental Science and Technology 35:3294-3301.

Bouma, J. 2002. Land quality indicators of sustainable land management across scales. Agriculture, Ecosystems and Environment 88(2):129-136.

Bouma, J., H. W. G. Booltink, and A. Stein. 1996. Reliability of soil data and risk assessment of data applications. Soil Science Society of America Special Publication 47:677.

Cressie, N. A. C. 1993. Statistics for spatial data. John Wiley, New York 900.

Desaules, A., J. Sprengart, G. Wagner, H. Muntau, and S. Theocharopoulos. 2001. Description of the test area and reference sampling at Dornach. The Science of the Total Environment 264:17-26.

Deutsch, C. V., and A. G. Journel. 1998. GSLIB Geostatistical software library and user's guide. ., New York 369.

Dubois, J.-P., and R. Schulin. 1993. Sampling and analytical techniques as limiting factors in soil monitoring. Pages 271-273 in R. Schulin, A. Desaules, R. Webster, and B. von Steiger. Eds, Soil monitoring-early detection and surveying of soil contamination and degradation. Birkhäuser, Basel.

Fresenius, W., A. Kettrup, and R. W. Scholz. 1995. Grössenordnung Faktor 2: Zur Genauigkeit von Messungen bei Altlasten. Altlasten Spektrum 4:217-218.

Geiger G., and R. Schulin (1995) Risikoanalyse, Sanierungsund Überwachungsvorschläge für das schwermetallbelastete Gebiet von Dornach. Berichte 2. Volkswirtschaftsdepartement des Kantons Solothurn, Amt für Umweltschutz, Solothurn, 79 pp

Geovariances. (1997) Isatis. Geostatistical software. Version 3.1.2. Avon

Goovaerts, P. 1997. Geostatistics for natural resources evaluation. Oxford University Press, New York 483.

Goovaerts, P. 2000. Estimation or simulation of soil properties? An optimization problem with conflicting criteria. Geoderma 97:165-186.

Goovaerts, P. 2001. Geostatistical modelling of uncertainty in soil science. Geoderma 103:3-26.

Goovaerts, P., and V. Meirvenne. 2001. Delineation of harzard areas and additional sampling strategy in prescence of a location specific threshold. Pages 125-136 in A. Soares, J. Gomez-Hernandez, and J. Froidevaus. Eds, geoENVIIIgeostatistics for environmental applications. Kluwer Academic Publishers, Dordrecht.

Goovaerts, P., R. Webster, and J.-P. Dubois. 1997. Assessing the risk of soil contamination in the Swiss Jura using indicator geostatistics. Environmental and Ecological Statistics 4:31-48.

Gotway, C. A. 1994. The use of conditional simulation in nuclear-waste-site performance assessment. Technometrics 36:129-140.

Gotway C. A., B. M. Rutherford (1993) Stochastic simulation for imaging spatial uncertainty: comparison and evaluation of available algorithms. Pages 1-21 in Geostatistical Simulations. Fontainebleau, France.

Grunewald, K. 1997. Grossräumige Bodenkontamination. Springer, Berlin 250.

Gysi C., S., Gupta W., Jäggi J. -A. Neyroud (1991) Wegleitung zur Beurteilung der Bodenfruchtbarkeit. Eidgenössische Forschungsanstalt für Agrikulturchemie und Umwelthygiene, Liebefeld-Bern, 89 pp.

Hendriks, C., R. Obernosterer, D. Muller, S. Kytzia, P. Baccini, and P. H. Brunner. 2000. Material flow analysis. Case studies on the city of Vienna and the Swiss lowlands. Local Environment 5:311-328.

Hesske, S., M. Schärli, O. Tietje, and R. W. Scholz. 1998. Zum Umgang mit Schwermetallen im Boden: Falldossier Dornach. Pabst Science Publishers, Lengerich 145. 
Journel, A. G. 1974. Geostatistics for Conditional Simulation of Ore Bodies. Economic Geology 69:673-68.

Journel A. G. (1989) Fundamentals of geostatistics in five lessons. American Geophysical Union, Washington, DC, 40 pp.

Journel, A. G., and C. J. Huijbregts. 1978. Mining geostatistics. Academic Press, London 599.

Keller, A., B. von Steiger, S. E. A. T. M. van der Zee, and R. Schulin. 2001. A stochastic empirical model for regional heavy-metal balances in agroecosystems. Journal of Environmental Quality 30:1976-1989.

Keller, A., K. Abbaspour, and R. Schulin. 2002. Assessment of uncertainty and risk in modeling regional heavy metal accumulation in agricultural soils. Journal of Environmental Quality 31:175-187.

Limpert, E., W. A. Stahel, and M. Abbt. 2001. Log-normal distributions across the sciences: keys and clues. Bioscience 51:341-352.

Matheron, G. 1963. Principles of geostatistics. Economic Geology 58:1246-1266.

Meuli, R., O. Atteia, J. P. Dubois, R. Schulin, B. von Steiger, J.-C. Vedy, R. Webster (1994). Geostatistical interpolation in regional mapping of soil contamination by heavy metals. A case study comparing two rural regions in Switzerland. In FOEFL (ed.), Regional soil contamination surveying, environmental documentation., Federal Office of Environment, Forests and Landscape, Bern, pp 43.

Meuli R. G. (1997). Geostatistical analysis of regional soil contamination by heavy metals. Dissertation ETH No. 12121, Swiss Federal Institute of Technology Zürich, 191 pp.

Mowrer, H. T. 2000. Uncertainty in natural resource decision support systems: sources, interpretations, and importance. Computers and Electronics in Agriculture 27:139-154.

Muntau, H., A. Rehnert, A. Desaules, G. Wagner, S. Theocharopoulous, and P. Quevauviller. 2001. Analytical aspects of the CEEM soil project. The Science of the Total Environment 264:27-49.

Pan, G. 1997. Conditional simulation as a tool for measuring uncertainties in petroleum exploration. Nonrenewable Resources 6:285-293.

Papritz, A., and R. A. Moyeed. 1999. Linear and non-linear kriging methods: tools for monitoring soil pollution. Pages 304-340 in V. Barnett, A. Stein, and K. Feridun Turkman. Eds, Statistics for environment 4: pollution assessment and control. 4. John Wiley \& Sons, London.

Prato, T. 2000. Multiple attribute evaluation of landscape management. Journal of Environmental Management 60:325-337.

Ramsey, M. 1998. Sampling as a source of measurement uncertainty: techniques for quantification and comparison with analytical sources. Journal of Analytical Atomic Spectrometry 13:97-104.

Ramsey, M. H, and A. Argayraki. 1997. Estimation of measurement uncertainty from field sampling: implications for the classification of contaminated land. The Science of the Total Environment 198:243-257.

Ramsey M. H., A. Argyraki, S. Squire (1998) Measurement uncertainty arising from sampling contaminated land: a tool for evaluating fitness-for-purpose. In ConSoil'98. Edinburgh, UK, pp 221-240

Roe, E., and M. van Eeten. 2001. Threshold-based resource management; a framework for comprehensive ecosystem management. Environmental Management 27:195-214.

Saito H. and P. Goovaerts (2000). "Geostatistical Interpolation of Positively Skewed and Censored Data in a Dioxin-Contaminated Site". Environmental Science and Technology 34:4228-4235.

Saito H., and P. Goovaerts (2001). "Accounting for source location and transport direction into geostatistical prediction of contaminants". Environmental Science and Technology 35:4823-4829.

Schulin, R., R. Webster, and R. Meuli. 1994. Technical note on objectives, sampling design, and procedures in assessing regional soil pollution and the application of geostatistical analysis in such surveys. Federal Office of Environment, Forests and Landscape, Bern 31.

Schweizerische Meteorologische Anstalt (1982-91). Klimaatlas der Schweiz. Atlas climatologique de la Suisse. Atlante climatologico della Suizzera. Lfg. 1-4, Verlag des Bundesamtes für Landestopographie, Wabern, Bern.

Stahel, W. A. 2000. Statistische Datenanalyse. Vieweg, Braunschweig/Wiesbaden .:380

Theocharopoulos, S. P., G. Wagner, J. Sprengart, M. -E. Mohr, A. Desaules, H. Muntau, M. Christou, and P. Quevauviller. 2001. European soil sampling guidelines for soil pollution studies. The Science of the Total Environment 264:51-62.

Thompson, M. 1995. Uncertainty in an uncertain world. Analyst 120:117-118.

Thompson, M., and T. Fearn. 1990. What excatly is fitness for purpose in analytical measurement?. Analyst 121:273-278.

Tietje O. (1993) Räumliche Varibilität bei der Modellierung der Bodenwasserbewegung in der ungesättigten Zone. PhD. thesis. Technische Universität Braunschweig, 117 pp.

Tiktak, A., A. Leijnse, and H. Vissenberg. 1999. Uncertainty in a regional-scale assessment of cadmium accumulation in the Netherlands. Journal of Environmental Quality 28:461-470.

Tuchschmid M. P. (1995) Quantifizierung und Regionalisierung von Schwermetall- und Flourgehalten bodenbildender Gesteine der Schweiz. Bundesamt für Umwelt, Wald und Landschaft, Umwelt-Materialien Nr. 32, Bern, 130 pp.

Van Meirvenne, M. 2001. Evaluating the probability of exceeding a site-specific soil cadmium contamination threshold. Geoderma 102:75-100.

VBBo (1998) Verordnung über Belastungen des Bodens vom 1. Juli 1998 (Swiss Ordinance on the Pollution of Soils). SR 814.12, Bern

von Holst, C. 1997. Beurteilung der Qualität von Analysendaten mit statistischen Methoden unter Berücksichtigung der Probennahme und der analytischen Bestimmung. Pages 139-145 in S. Schulte-Hostede, R. Freitag, A. Kettrup, and W. Fresenius. Eds, Altlasten-Bewertung, Datenanaylse und Gefahrenbewertung. ecomed, Landsberg.

von Steiger, B., R. Webster, R. Schulin, and R. Lehmann. 
1996. Mapping heavy metals in polluted soil by disjunctive kriging. Environmental Pollution 94:205-215.

Wächter, H. 1997. Möglichkeiten und Grenzen der Routineanalytik bei der Überprüfung von Schwellenwerten - Erfahrungen aus der Praxis eines Umweltlabors. Pages 30-43 in S. Schulte-Hostede, R. Freitag, A. Kettrup, and W. Fresenius. Eds, Altlasten-Bewertung, Datenanaylse und Gefahrenbewertung. ecomed, Landsberg.

Wagner, G., M. -E. Mohr, J. Sprengart, A. Desaules, H. Muntau, S. Theocharopoulus, and P. Quevauviller. 2001a. Objectives, concept and design of the CEEM soil project. The Science of the Total Environment 254:3-15.
Wagner, G., P. Lischer, H. Theocharopoulos, H. Muntau, A Desaules, and P. Quevauviller. 2001b. Quantitative evaluation of the CEEM soil sampling intercomparison. The Science of the Total Environment 264:73-101.

Webster, R. 2000. Is soil variation random?. Geoderma 97:149-163.

Webster, R., and M. A. Oliver. 2001. Geostatistics for Environmental Scientists. John Wiley \& Sons, Chichester 270.

Wirz E., and D. Winistörfer (1987) Bericht über Metallgehalte in Boden- und Vegetationsproben aus dem Raum Dornach. Kantonales Laboratorium Solothurn, Solothurn, 49 pp. 